\title{
UNUSUAL BEHAVIOUR INVOLVING MOURNING CLOAK BUTTERFLIES
}

PETER TAYLOR, P.O. Box 597, Pinawa, MB R0E 1L0. E-mail: <taylorp@granite.mb.ca>

The Mourning Cloak's large size, unique wing pattern, nationwide distribution, and long flight period make it one of the most familiar Canadian butterflies. During 2007, I twice observed unusual behaviour involving Mourning Cloaks in southeastern Manitoba (near $50^{\circ} \mathrm{N}, 96^{\circ} \mathrm{W}$ ): once as the object of courtship of another butterfly species, and once in an unusual feeding situation. The dates correspond to the normal spring and midsummer flight periods for this species in the area.

At about 4 p.m. on 15 April, while driving slowly along a gravel road northwest of Pinawa, I saw a Mourning Cloak and a Milbert's Tortoiseshell together at a small, wet spot on the roadway. Stopping for the photo opportunity, I was struck by how close the tortoiseshell stayed to the Mourning Cloak. When they flushed, it flew about $30 \mathrm{~cm}$ behind its larger relative, following every zig and zag, then landed close by and edged up behind it until almost touching (Fig. 1). It was not just a case of both being attracted to the same spot in the road; the tortoiseshell was evidently attracted to the Mourning Cloak.

I thought at first that the tortoiseshell sought the larger, dark-coloured butterfly for warmth and shelter on a relatively cool (about $15^{\circ} \mathrm{C}$ ), breezy afternoon. A more anthropomorphic thought was that they were "buddies", newly emerged from hibernation, enjoying the first warmth of spring together. I then realized that the behaviour was similar to that of a courting pair of Milbert's Tortoiseshells I had photographed near Pinawa on 27 June 2006 (Fig. 2). Most likely this was an example of interspecific courtship, perhaps prompted by the absence of an appropriate mate on a day with little butterfly activity at the very beginning of the flight period. Courtship between different butterfly species, sometimes not even closely related, is apparently "encountered surprisingly frequently in field work with butterflies", though seldom reported..$^{1-3}$ In this instance the butterflies belonged to the same genus, Nymphalis.

The second observation was at a gravel road near the Canadian Pacific Railway main line between Whitemouth and Rennie at about 3 p.m. on 15 July. There, I was enjoying a combination of picking berries, photographing butterflies, and watching freight trains roll by. A Mourning Cloak caught my attention when it landed on the sunlit rear tire of my van. At first this seemed to be just a warm, sheltered spot to bask. On closer observation, however, the butterfly appeared to be feeding on the surface of the tire (Fig. 3). It then sidled into the shade of the wheel well and continued to feed by probing in the grooves of the tire treads.

There was no visible moisture on the tire; the gravel road was mainly dry, and the van had been parked for over an hour in sunny, breezy conditions. Mourning Cloaks are generally described as sap feeders, and like many butterfly species they are also 


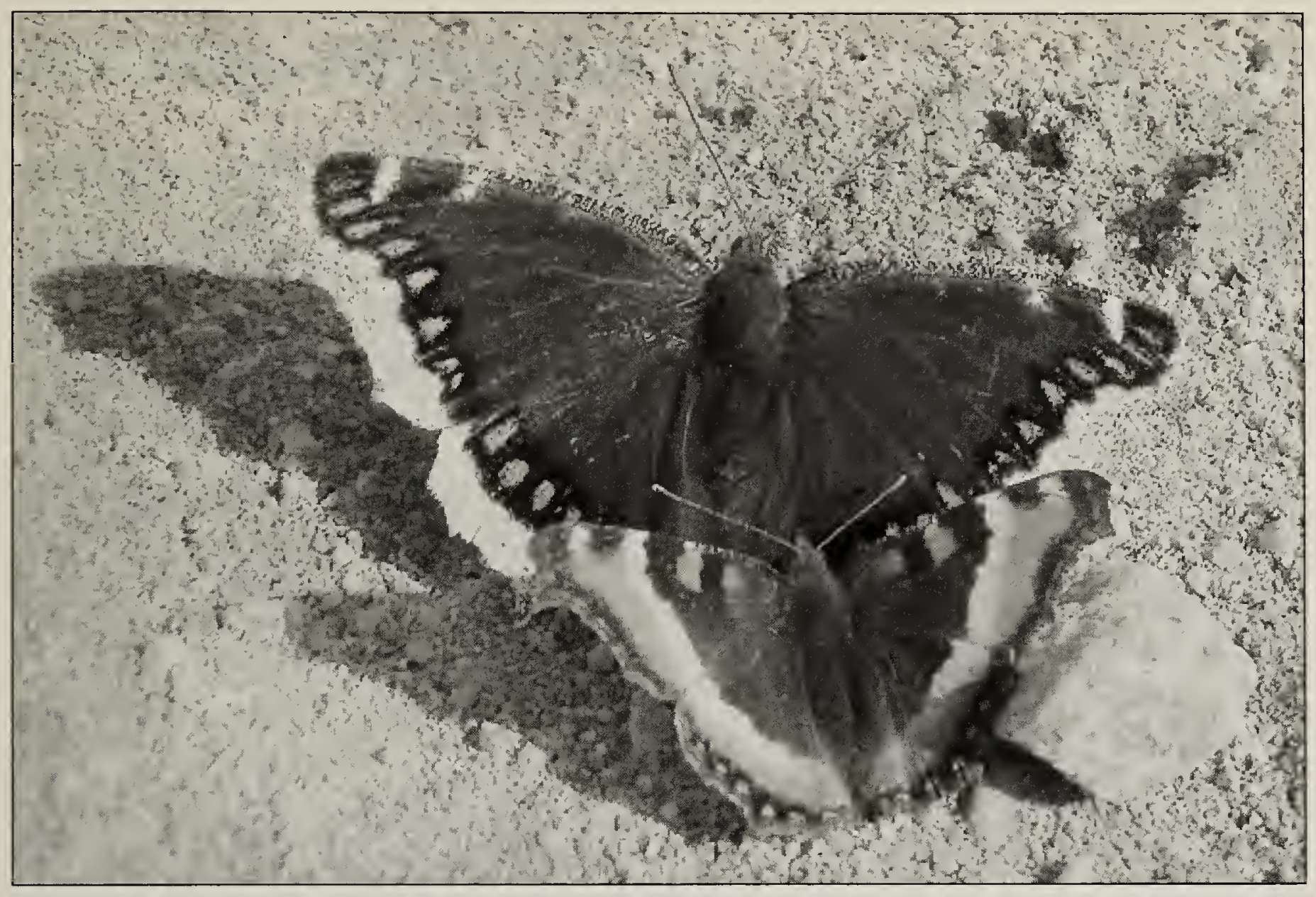

Figure 1

Peter Taylor

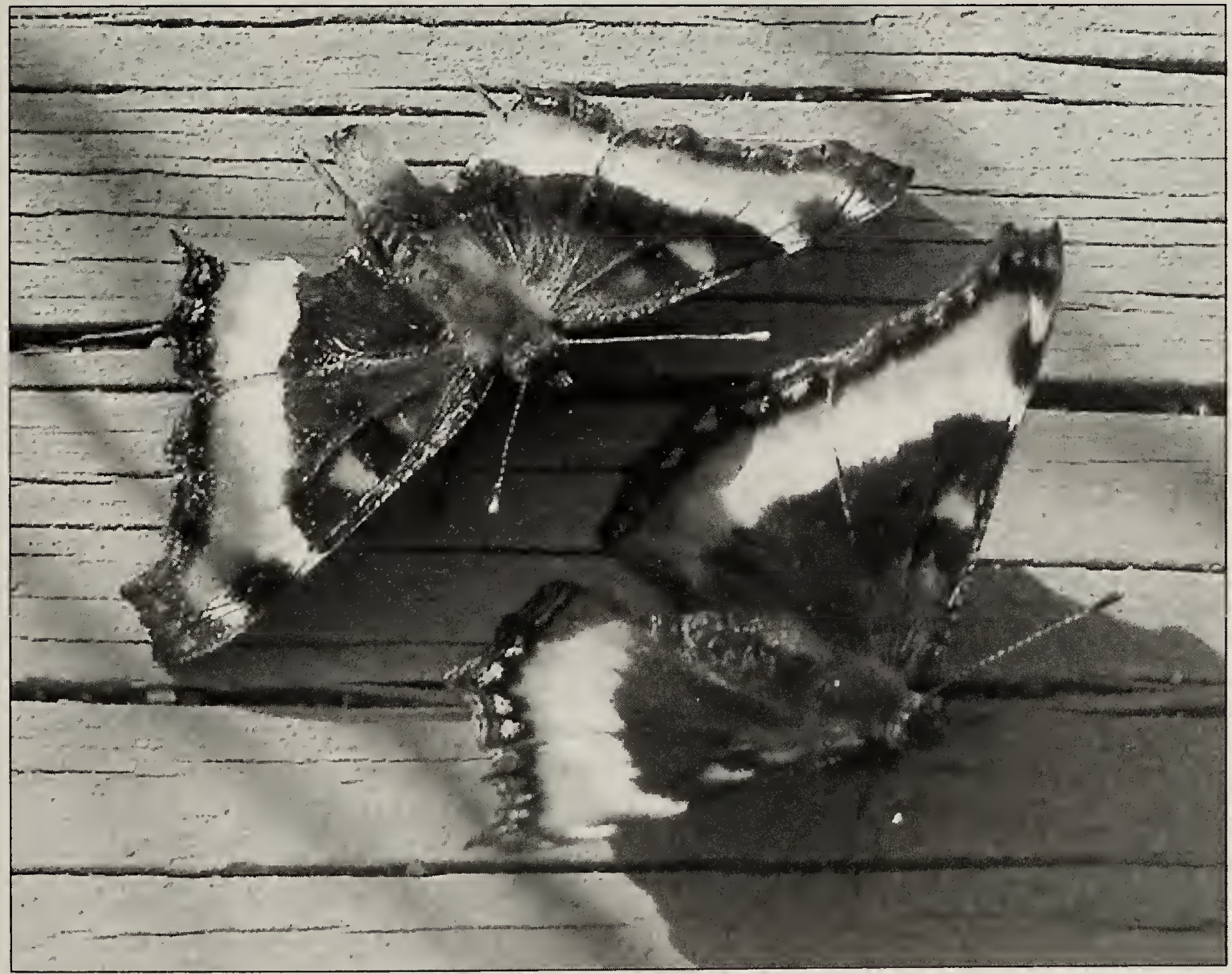

Figure 2

Peter Taylor

65 (3) September 2007 
known to feed on decaying organic material such as carrion, dung, and rotting fruit. One can only imagine what traces of edible matter, or perhaps salt, the butterfly was finding in this unusual feeding niche.

1. SHAPIRO, A.M. 1973. An interfamilial courtship (Nymphalidae, Pieridae). Journal of Research on the Lepidoptera 11:197-198.
2. SHAPIRO, A.M. 1981. An interfamilial courtship (Lycaenidae, Pieridae). Journal of Research on the Lepidoptera 20:54.

3. SHAPIRO; A.M. 1985. An intersubfamilial courtship (Lycaenidae). Journal of Research on the Lepidoptera 24:195.

NOTE: Articles published in Journal of Research on the Lepidoptera can be viewed online at: http:/ /www.doylegroup.harvard.edu/ carlo/JRL/jrl.html

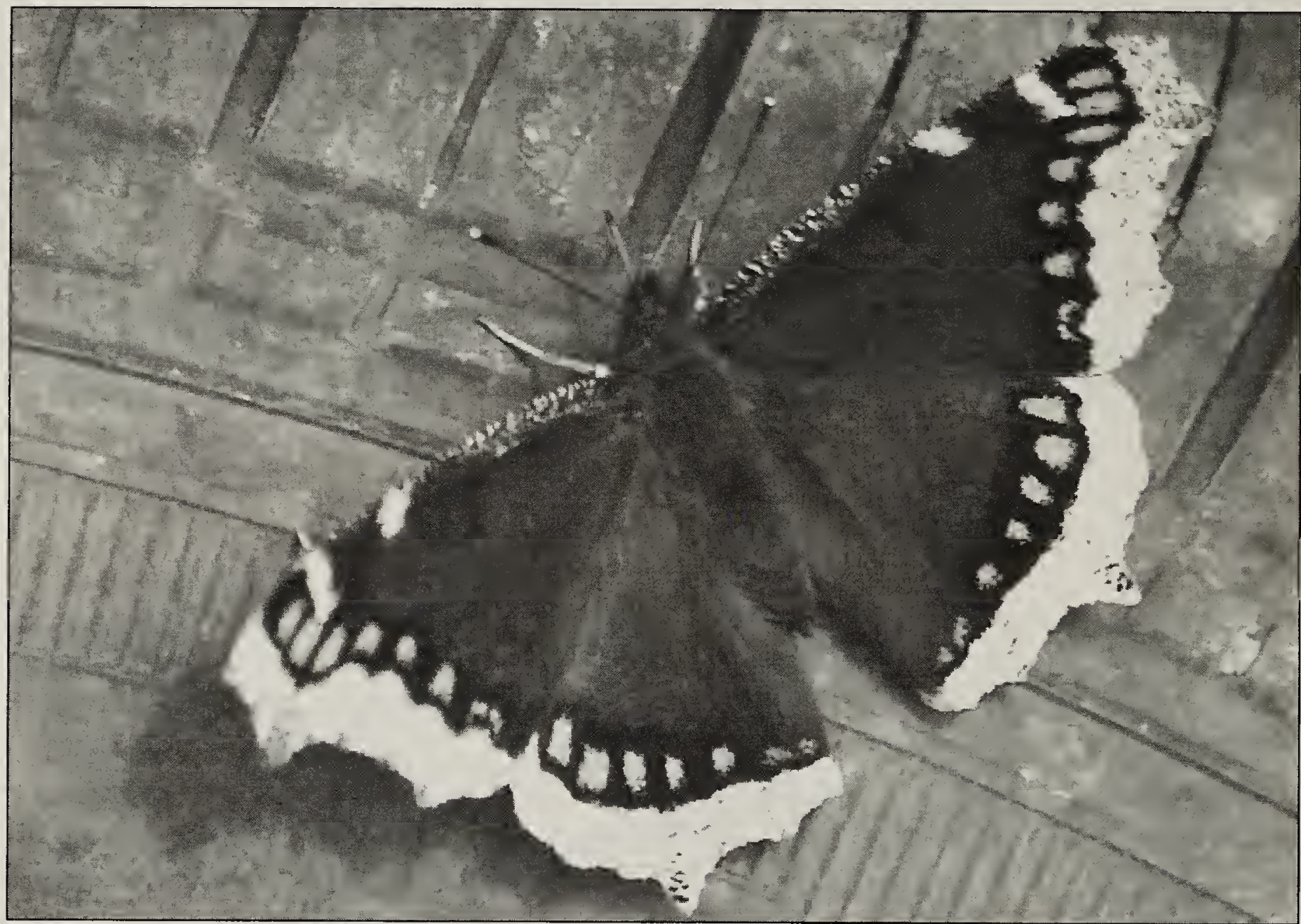

Figure 3

Peter Taylor

"When I walk now I bring home a harvest of burs and stick-tights on my trouser legs and socks. Even a brief walk at the roadside or in the pasture gathers half a dozen different kinds. Plucking them off, I marvel at the variety of ingenious ways a seed can hitch a ride."

Hal Borland, Beyond Your Doorstep, p. 349. 